\title{
OSTEOCHONDRODYSTROPHIA DEFORMANS (MORQUIO BRAILSFORD DISEASE)
}

BY

\author{
N. FELDMAN and M. E. DAVENPORT \\ From the Coronation Hospital, Johannesburg
}

(Received for Publication September 25, 1950 )

In 1929 Morquio described an osseous dystrophy in a family, in which four out of five siblings were affected. In 1931 Brailsford described the radiological features of the disease. Since then about 40 additional cases have been reported in subjects all of European descent. Of the four cases presented in this paper, two are pure Africans and two are of mixed European-African racial origin.

Little is known about the aetiology or pathology of the disease except that many of the cases show a familial and hereditary tendency, but in some instances only a single member of a family has been affected. Shelling (1947) is of the opinion that a dominant Mendelian factor is involved as in achondroplasia, but in the family described by Jacobsen (1939) 20 members belonging to five generations were affected; the hereditary trait appeared to be a sex-linked recessive character. Consanguinity of parents and paternal grandparents was reported by Morquio, but this has not been a feature of all the cases described. In three of our cases a history of consanguineous parents was obtained.

\section{Case Reports}

Cases 1 and 2. The subjects reported here are both female siblings (Fig. 1). They are the eldest (7 years) and the youngest ( 1 year 2 months) of three sisters. The unaffected sibling, aged 3 years, is apparently normal in every respect and shows no radiological changes in the skeleton. Both the affected children were full term normal infants at birth, were breast fed, and sat up, crawled, and walked at the normal age. In both, the mother noticed that from about the age of 1 year they had difficulty in breathing because of 'blocked noses.'

The mother is of pure Bantu stock but the father is coloured (mixed). The parents' mothers were first cousins. Neither can recall any deformity in members of their respective families. Both parents are healthy. Before the birth of the first child the mother had a premature labour at 32 weeks. During her subsequent pregnancies she enjoyed good health and her deliveries were all normal.

CASE 1. T.M., a girl aged 7 years, sat up at $6 \frac{1}{2}$ months, crawled at 7 months, and walked before the age of a year.
At the age of 3 years the mother noticed that the child was ' knock-kneed and had swelling of her wrists'. She had always had a blocked nose and nasal discharge. At the age of 4 years her tonsils were removed.

Examination revealed a well nourished, intelligent, and cooperative child. The head appeared large, the circumference 21 in. (normal 201 in.). The hair was dry and wiry, the eyelashes long and curled, the nose broad and flattened at the base. The external nares were filled with thick discharge. The enamel of the

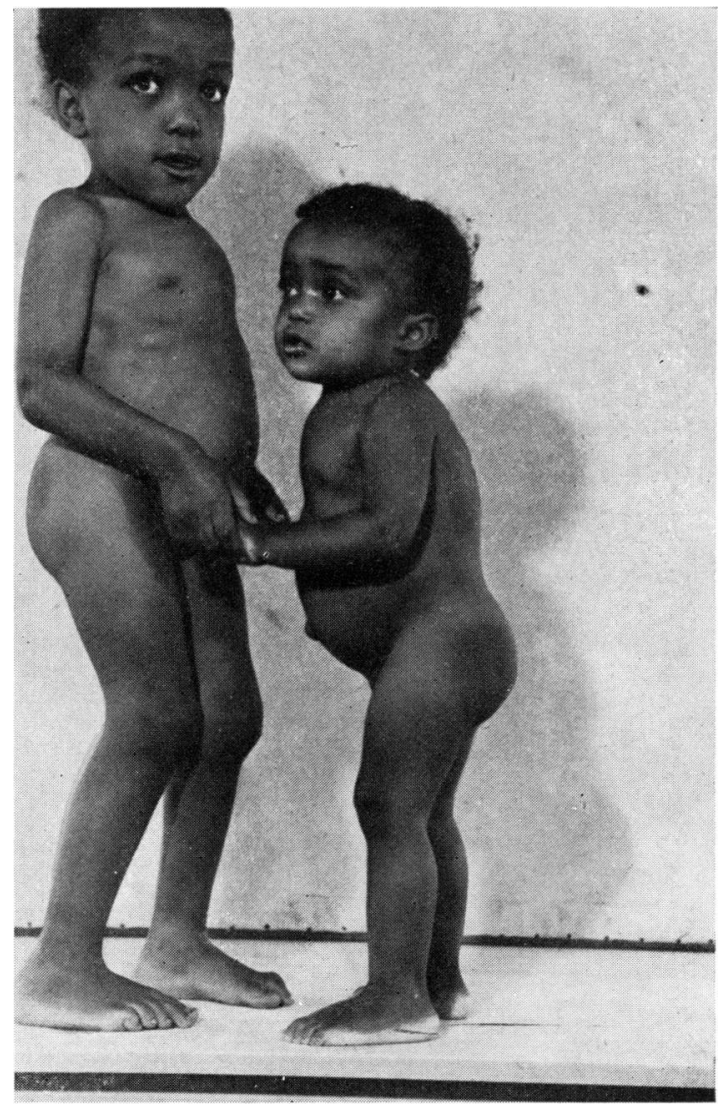

FiG. 1 
teeth was poorly calcified especially on the incisors; the dental eruption was normal for the age. The pharynx was congested and there was a thick post-nasal drip. No abnormalities were noted in the heart, lungs, abdomen, or central nervous system.

The standing height was 36 in. (normal 46 in.), the sitting height 20 in. (normal 23 in.), and the weight $32 \mathrm{lb}$. (normal $50 \mathrm{lb}$.). The standing position was one of

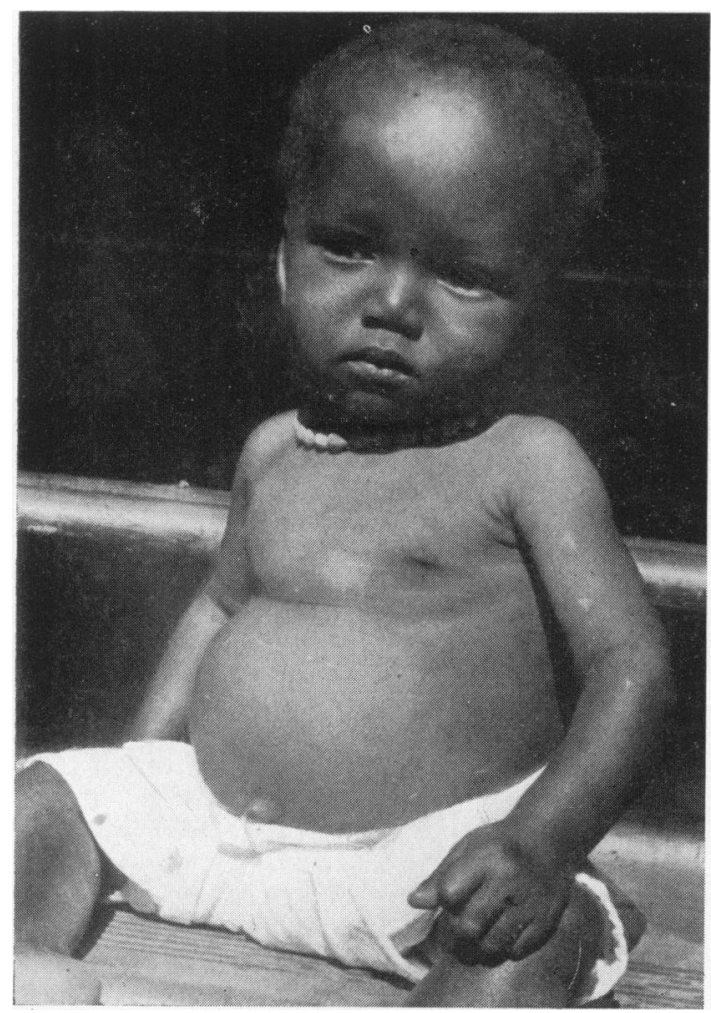

FIG. 2a

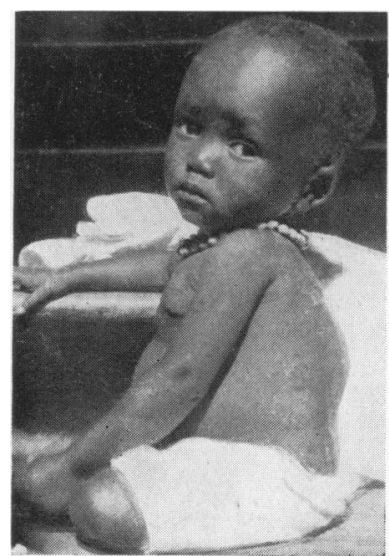

FIG. 2b semi-crouching with the knees flexed, and the gait was waddling and on a broad base.

The chest was deformed with deep Harrison's grooves.

The costochondral junctions were bulbous and the deformity of the pigeon chest was most obvious in the upper sternum. The neck was short and the chin one inch above the sternum. There was splaying of the costal margins.

The abdomen was pot-bellied and there was kyphosis of the lower dorsal region.

The cubitus valgus, ulnar deviation of the wrists, and radial deviation of the phalanges gave the limbs a zig-zag appearance.

Crepitus was present in both shoulder and elbow joints. Extension was limited at the elbow joints and radial deviation at the wrist joints.

The transverse diameter at the ends of the bones was increased, especially at the wrists.

There was an extreme degree of bilateral genu valgum and pes planus. Extension was limited at the knees and eversion at the ankles. There was varus deformity and crepitus at both ankles. The patellae were present and normal. The epiphyseal enlargements were not as pronounced as in the upper extremities. Muscular power was good in all limbs.

CASE 2. J.M., a girl aged 14 months, sat up at 6 months, walked at 1 year, cut the first tooth at $6 \frac{1}{2}$ months. She was unable to talk. For the past three months her nose had been blocked and her respiration had been noisy. At 10 months her mother noticed that her back was becoming hunched.

Examination revealed a well nourished child (Figs. 2a and b). The skull appeared large; circumference $18 \frac{3}{4}$ in (normal 181 in.). The anterior fontanelle had a diameter of $2 \mathrm{~cm}$. The nose was flat and the bridge depressed. The external nares were filled with thick mucopus. The pharynx was congested and the tonsils enlarged. The neck was short.

The chest wall bulged anteriorly, the costochondral junctions were thickened and there were well marked Harrison's grooves. The heart was not clinically enlarged and the heart sounds were normal. The air entry to the lungs was poor. There was an impairment of the percussion note at the right base and the breath sounds were diminished on the right side. The abdomen was protuberant with an umbilical hernia. The liver was enlarged 2 in. below the costal margin.

The wrist epiphyses were thickened and there was slight anterior bowing of the tibiae. There was only slight genu valgum, and valgus deformity at the ankles. There was kyphosis, most marked in the lumbar region, and a lateral scoliosis.

The deformities at the other joints were similar to those described in case 1 , but of a very much lesser degree.

Case 3. The patient was the youngest of a family of six children aged 20,15,11, 7, and 1 year and 8 months respectively. He was the second born of a twin delivery. The siblings were all healthy and were not deformed. Both parents were healthy and of pure Bantu stock. Neither could recall any deformity among members of their respective families. The parents were first cousins.

N.M., a boy, aged 20 months, was admitted to the 
ward in May, 1948, with a provisional diagnosis of tuberculosis of the spine. Since birth his growth and development had been slower than his twin brother's. The mother noticed that at the age of 3 months his back was not straight. From the age of 5 months the twins attended the local child welfare clinic. The records there show that at the first attendance N.M. weighed $7 \mathrm{lb} .15 \mathrm{oz}$. and his brother weighed $8 \mathrm{lb}$. $10 \mathrm{oz}$. A year later the patient weighed $12 \mathrm{lb}$. and his brother $16 \mathrm{lb}$. The patient started to crawl at the age of 7 months, had two teeth at one year, and on admission could only stand supported, and when assisted walked very unsteadily on a broad base. His twin brother walked well at 14 months.

The patient appeared moderately well nourished but was small for his age. The skull showed bossing of the frontal and parietal regions. The circumference was $18 \frac{1}{2}$ in. (normal $18 \frac{1}{2}$ in.). The anterior fontanelle was open and the diameter was $1 \frac{1}{2}$ in. The posterior fontanelle was closed. The root of the nose appeared depressed and the inter-orbital diameter was $\frac{7}{8}$ in.

The thoracic cage showed bilateral well-formed Harrison's grooves, with a pigeon breast deformity, the most prominent anterior projection being at the level of the nipples.

The abdomen was 'pot bellied' with a circumference of $19 \frac{1}{2}$ in. : the liver was enlarged and firm, the edge being palpable $1 \frac{1}{2}$ in. below the costal margin. There was prominent kyphosis in the lower dorsal area. The upper extremities showed no deformity and the lower extremities were thin but not deformed.

Case 4. E.T. was a boy aged 10 years (Fig. 3). His father died when the patient was 3 years old. His three siblings by his mother's second husband were normal. There was no evidence of deformities in the patient's parents or in their families. The mother was of pure Basuto and the father of pure Xosa stock. The parents were not consanguineous.

The mother stated that pregnancy and delivery were normal and that it was only at the age of 14 days that she noticed that he had a deformity of the back. He was admitted for this complaint to a hospital where he remained for three months, without improvement. His development, both physical and mental, was very slow. He started to walk at the age of 2 years, and speech started only when he was 5 years old. He was mentally retarded and was in a junior grade class at school.

The patient was well nourished, and his stature was small for his age (standing height 44 in.). The skull appeared large, the circumference 22 in. (normal 21 in.), and the nose flat. The intra-orbital diameter was $1 \frac{1}{3}$ in. The teeth were normally developed. There was no gross deformity of the chest, the circumference of which was 23 in. The costochondral junctions were more prominent than normal. No abnormality was detected in the heart, lungs, or abdomen.

There was marked kyphosis in the upper dorsal region with a large dimple $\frac{1}{2}$ in. by $\frac{1}{4}$ in. over the spine of the ninth thoracic vertebra. The neck appeared short as a result of the kyphosis. The extremities appeared normal except for the hands which were small and the fingers short and stubby. There was slight ulnar deviation at the wrists and slight inversion of the feet. There was no limitation of movement or crepitus at any of the joints.

\section{Blood Chemistry}

Two of the cases described by Morquio had blood calcium levels of $5 \cdot 2 \mathrm{mg}$. and $4.5 \mathrm{mg}$. respectively. As a result of these findings he stated:

- Radiography visualizes the characteristics of the osseous changes, presenting a profound alteration in osteogenesis explicable by the great diminution of the blood calcium.' (Morquio, 1929)

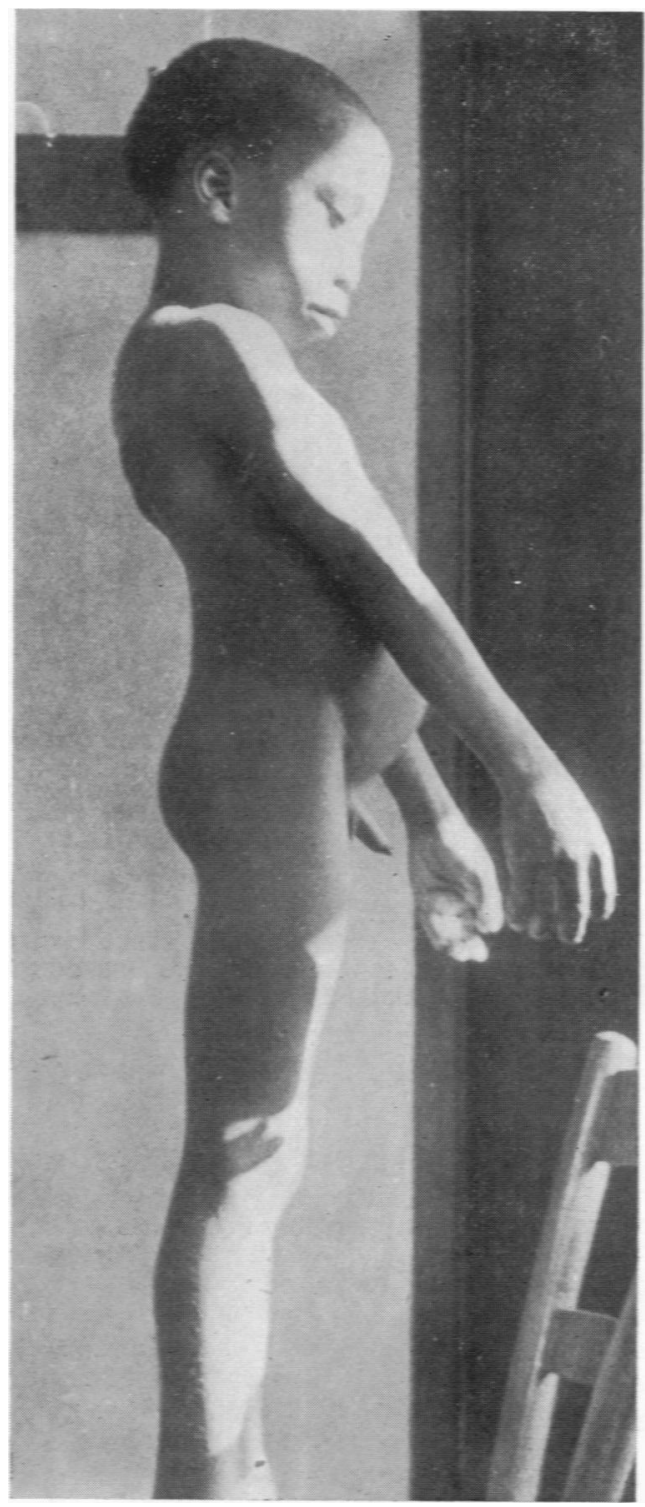

Fig. 3 


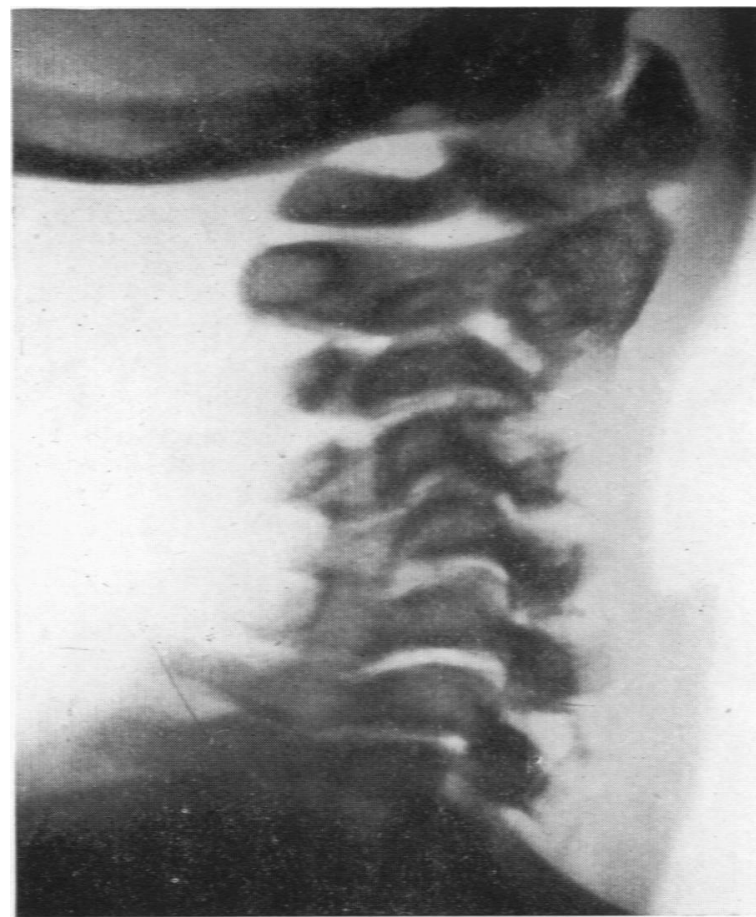

FIG. 4

Fig. 4.-Radiograph showing loss of normal cervical lordosis and irregularity of cervical bodies in Case 4.

FIG. 5a.-Radiograph showing the dorso-lumbar kyphosis with anterior tongue-like projections of the lumbar vertebrae in Case 1 . The bodies are irregular in size.

Fig. 5b.-Radiograph showing the dorso-lumbar kyphosis and anteriorly tapering bodies in Case 2.

FIG. 5a 

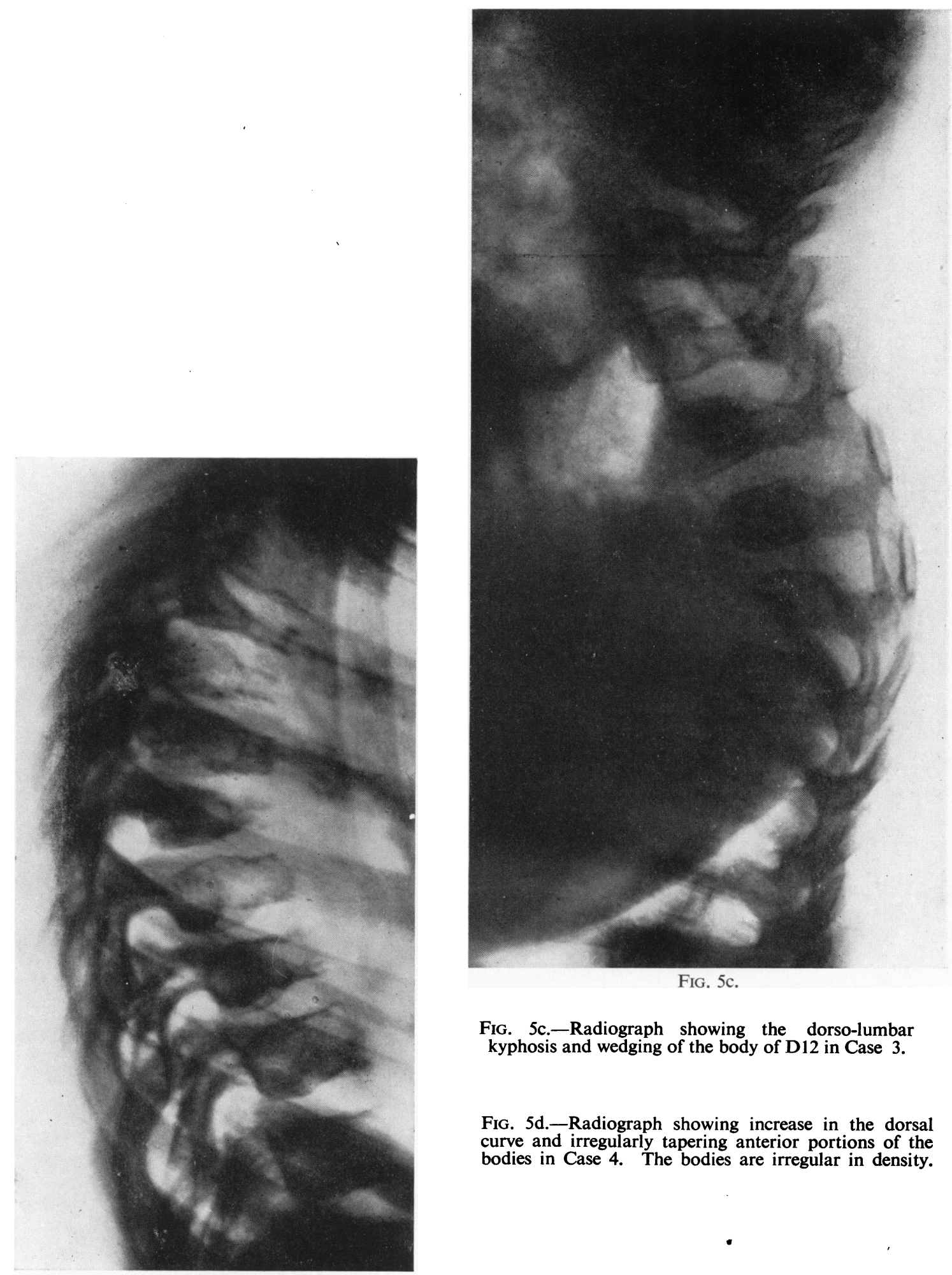

FIG. 5c.

FIG. 5c.-Radiograph showing the dorso-lumbar kyphosis and wedging of the body of D12 in Case 3.

FIG. 5d.- Radiograph showing increase in the dorsal curve and irregularly tapering anterior portions of the bodies in Case 4 . The bodies are irregular in density.

FIG. 5d. 


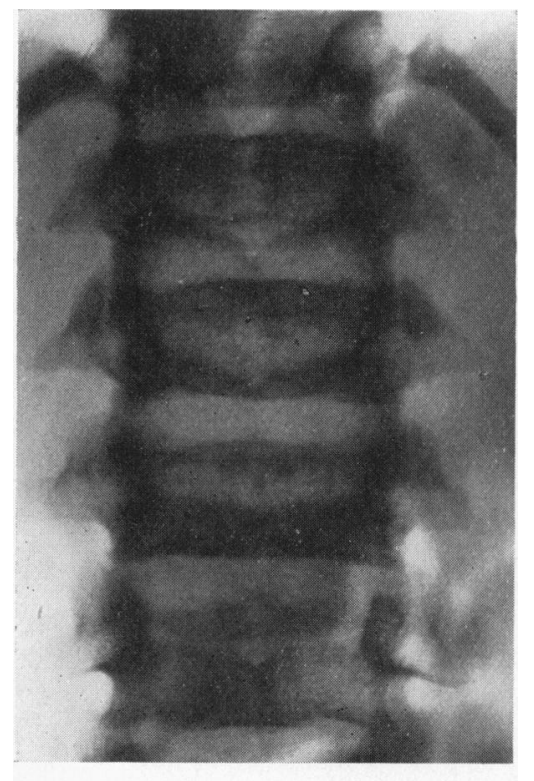

FIG. 6

FIG. 6.-Radiograph showing that the vertebral bodies are wide and flattened and their structure indefinite (Case 4).

The disc spaces are widened.

FIG. 7a and b.-Radiograph shows the irregularly expanded diaphyses of the radius and ulna with overgrowth in length of the radius (Cases 1 and 2).

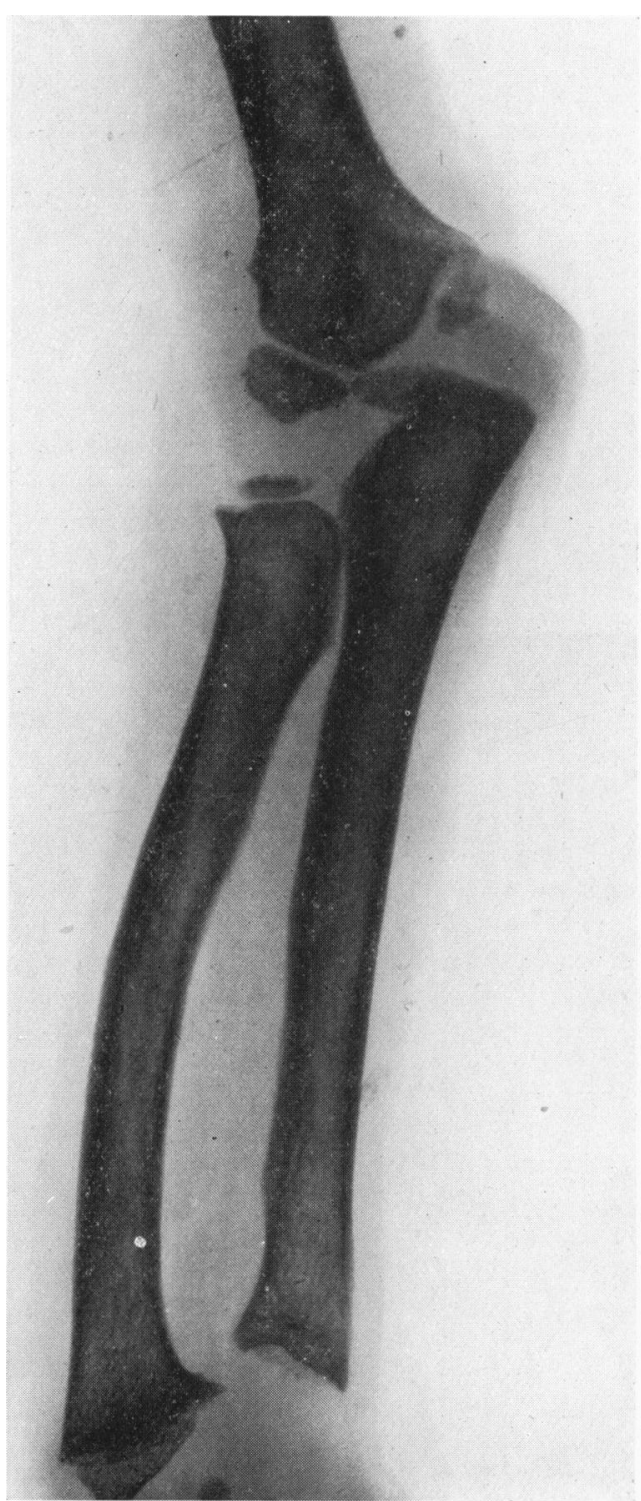

FIG. 7a 


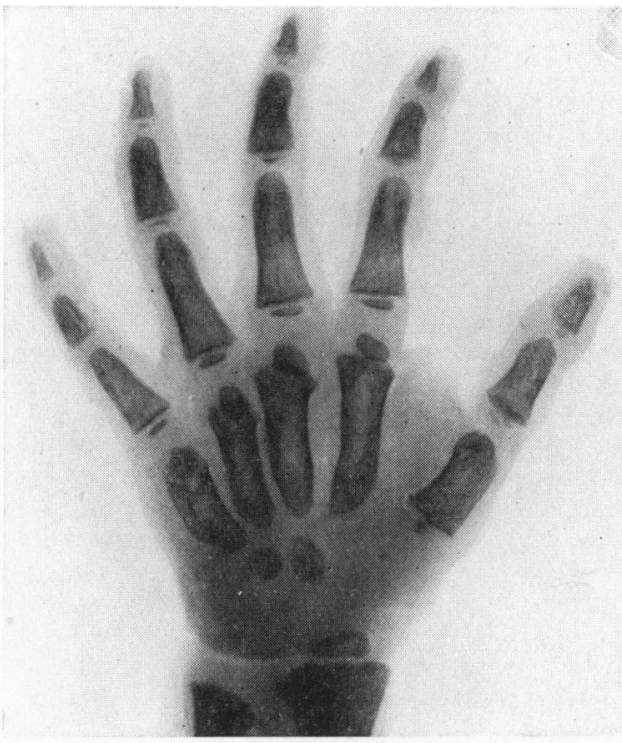

FIG. 8a and b.-Radiographs showing that the metacarpals are stunted with irregular diaphyses (Cases 1 and 2). The trabeculation is irregular. The phalanges are short and thick.
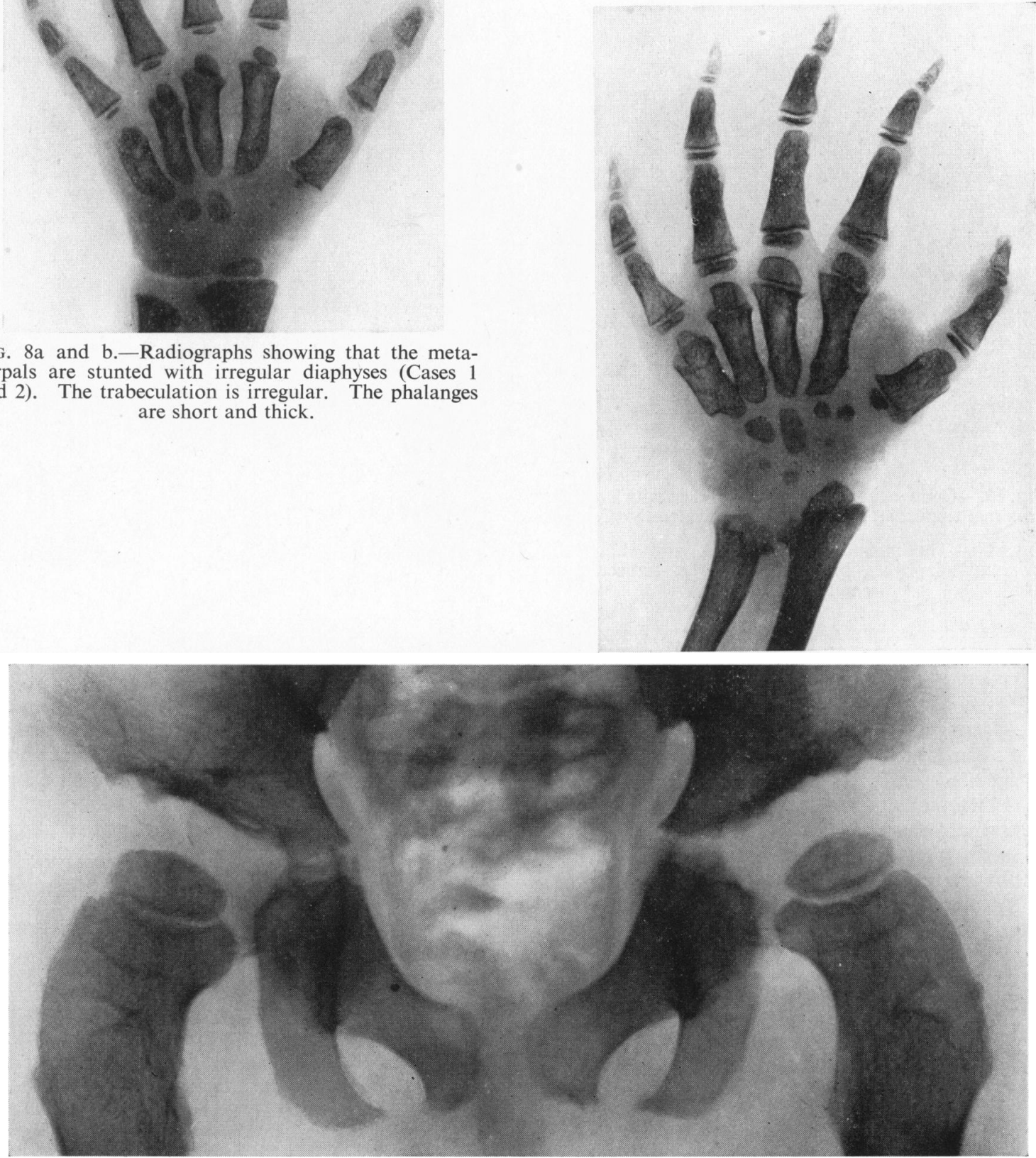

Fig. 9.-Radiograph showing that the acetabuli are wide and irregular and the hip joint spaces widened (Case 1).

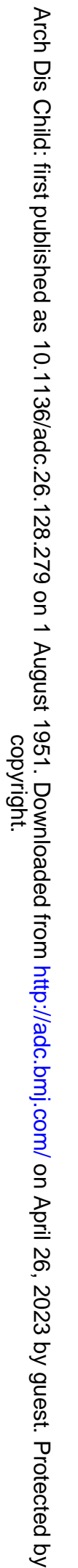




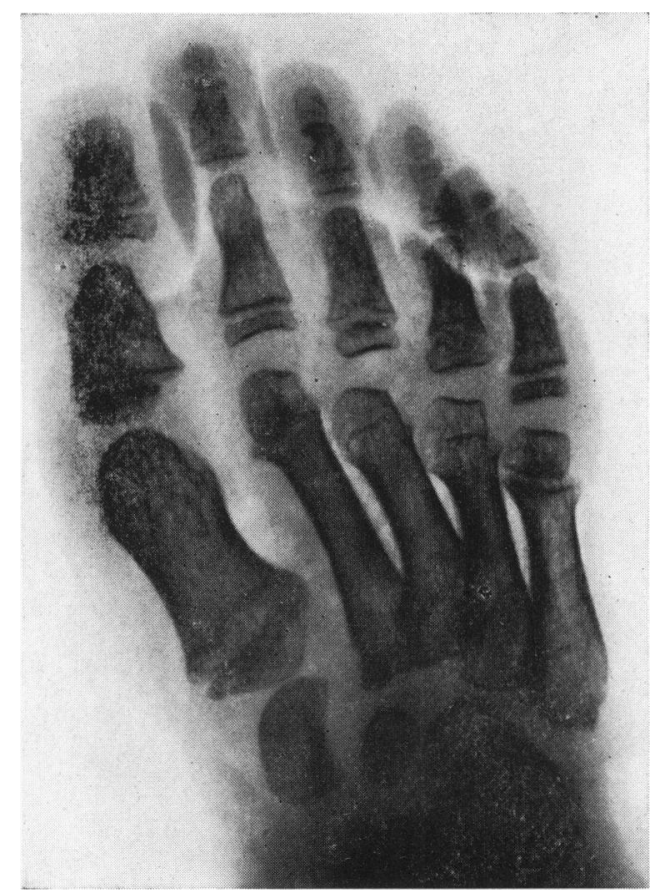

FIG. 11.

FIG. 10.-Genu valgum deformity is shown with irregular proximal tibial diaphyses which slope laterally (Case 1).

Fig. 11.-The metatarsals are thick and short, the proximal diaphyses irregular, and the trabeculation coarse (Case 1).

Hypocalcaemia does not appear to be present in the majority of the other cases described. Shelling (1947) found values varying from $8.7 \mathrm{mg}$. to $12 \cdot 8 \mathrm{mg}$. Meyer and Brennemann (1932) reported a case in which the blood calcium value was $12.8 \mathrm{mg}$. at the age of 5 years and $10.8 \mathrm{mg}$. at the age of $6 \frac{1}{2}$ years. In eight cases described by Ruggles (1931) the blood calcium was normal. Similarly normal values have been found in respect of blood sugar, phosphorus, cholesterol, and alkaline phosphatase estimations in the reported cases. The blood chemical investigations in our cases are shown in Table 1.

The abnormal values for the serum proteins and the slight anaemia are both probably due to the poor nutrition (low protein diets) of most African native children.

\section{Radiological Findings}

Alterations in Curvature. The four cases described all showed alterations in curvature. In case 1 there was loss of the normal cervical lordosis. Cases 1,

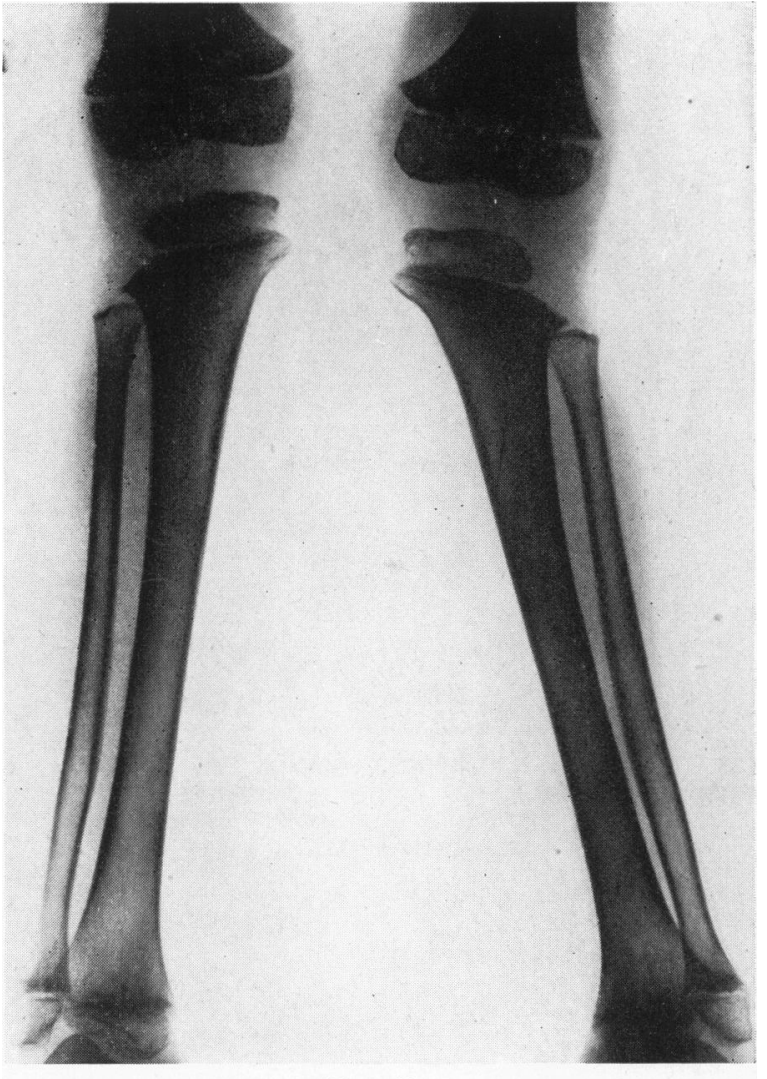

FIG. 10.

2, and 3 showed a kyphosis at the level of D11 and 12. Case 4 showed no dorso-lumbar kyphosis, but the normal dorsal curve was increased.

In case 1 the vertebral bodies of $\mathrm{C} 3,4,5,6$, and 7 were irregular in density and their anterior portions ragged and frayed. The dorsal vertebrae in all the cases were irregular in outline, tapering anteriorly, some showing anterior tongue-like projections. The disc spaces were widened, and the epiphyseal plates in case 4 were irregular. Cases 1,2 , and 3 showed the lumbar spinous processes to be short and stunted.

In the antero-posterior projection the vertebral bodies appeared wide and flattened and their structure indefinite.

Skull. In two of the cases the calvarium appeared large, and in case 1 there was basilar impression and the root of the nose was depressed. In case 2 the skull showed no obvious abnormality.

Chest and Ribs. The antero-posterior diameter of the chest was increased, and the anterior ends of the ribs expanded and somewhat irregular. 
TABLE 1

Blood Chemistry InVestigations

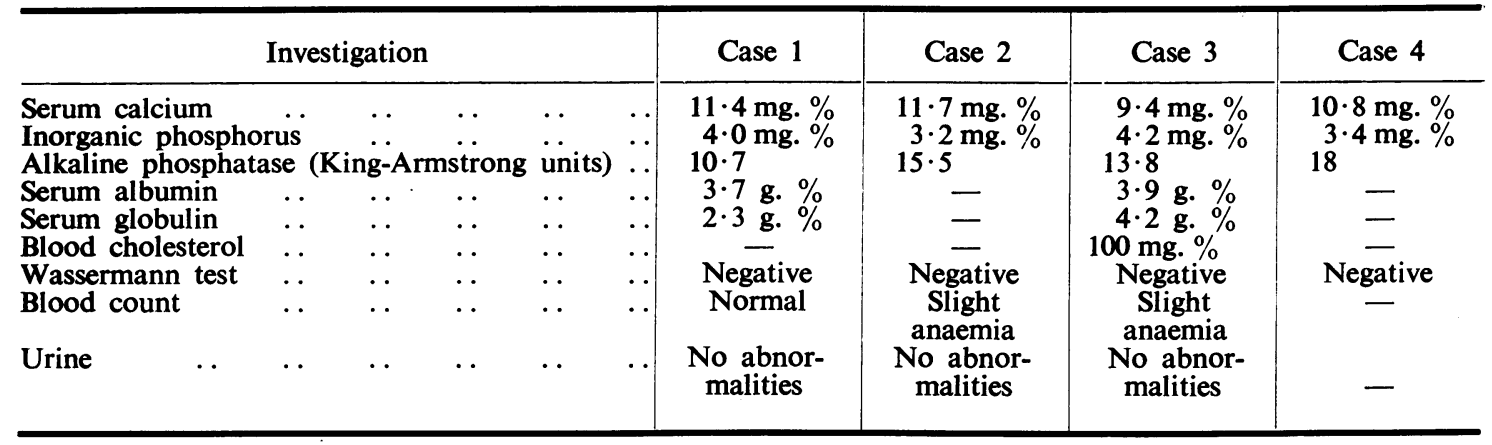

Shoulder Girdle. Cases 1 and 2 showed irregularity of the glenoid cavity, and in case 1 the coracoid process appeared expanded.

Humerus. The shaft appeared thicker than normal and the proximal epiphyses irregular and uneven in density. The proximal end of the diaphyses was widened and the distal epiphyses fragmented and irregular.

Radius and Ulna. These appeared thicker than normal. The proximal and distal diaphyses were irregular and expanded and the articular surfaces sloped towards one another. Cases 1 and 2 showed overgrowth in length of the radius.

Metacarpals. These appeared stunted, with irregularity of the proximal and distal diaphyses, the proximal appearing tapered. The shafts showed irregular trabeculation.

Phalanges. These were short and thick and the distal phalanges were conical in shape.

Pelvis. The acetabuli were widened and irregular and the hip joint spaces widened.

Femora. The shafts appeared shorter and thicker than normal and the necks widened. These cases showed bilateral genu valgum, and in addition case 1 showed a marked coxa valga deformity, and the capital epiphyses were irregular in density. The distal end of the shaft was expanded and the knee joint spaces widened.

Tibia and Fibula. These appeared thick and short and the proximal end of the tibia expanded, irregular, and sloping laterally.

Metatarsals. Basically these bones showed the same features as the metacarpal bones. They appeared thick and short and the proximal ends irregular. There was splaying out of the distal ends of the shafts of all the metatarsal bones except the first. The trabeculation appeared coarse.

\section{Discussion}

Osteochondrodystrophia deformans is a rare familial disease which has hitherto been described in European subjects only. Two of our cases are African native children who have no evidence of European ancestry. In these children the disease is localized to the vertebral bodies with little involvement of the rest of the skeleton. Our other two cases are sisters whose father is of mixed European and African racial origin. They suffer from the generalized form of the disease with involvement of the whole skeleton. The blood chemical findings in our cases do not support the contention of Morquio that hypocalcaemia plays a dominant role in the production of the osseous changes. Although mental retardation is not a feature of the disease, one patient was mentally retarded. In addition, he had a dimple in the skin in the midline over the ninth thoracic vertebra. In a case of gargoylism described - by Ellis (1940) mental retardation, which is a feature of that disease, was not present. This patient also had a midline skin dimple in the region of the first lumbar vertebrae.

The purulent rhinitis which was such a troublesome feature in two of our cases has been described as a feature of gargoylism, where it is caused by the nasal malformation (Henderson, 1940). It is understandable, in view of these common signs and symptoms, why cases of Morquio Brailsford disease have been wrongly labelled gargoylism and vice versa.

Morquio Brailsford disease is probably due to a hereditary developmental defect in germ plasm and is a dyschondroplasia. The hereditary disturbances of regular cartilage growth manifest many different syndromes. They may be classified in four main groups, but it should be remembered that considerable overlapping may take place. The blood 
calcium, phosphorus and alkaline phosphatase blood levels are normal in all.

Group I. Hypoplasia of Cartilage. Achondroplasia results from the failure of normal cartilage development. It causes dwarfism and osseous changes in which the tubular bones become reduced in length and are trumpet-shaped. The epiphyses are normal. The vertebrae may occasionally show wedge-shaped deformities.

Group II. Irregular Cartilage Growth and Distribution. Multiple chondromata is a familial disorder characterized by the presence of bilateral symmetrical chondromata usually involving the phalanges and small bones of the hands and feet.

Ollier's disease is a dyschondroplasia which is recognized by the presence of non-ossified cartilage in the diaphyseal ends of bones. The distribution of the lesions is usually unilateral and facial asymmetry is present in many cases.

In diaphyseal aclasis, a familial disorder, there are exostoses covered by hyaline cartilage in the diaphyses of the long bones near the epiphyseal plates.

Group III. Hyperplasia of Cartilage Growth. This group contains osteochondrodystrophia deformans (Morquio Brailsford disease).

Group IV. Combinations of Chondrodysplasia with Ecto- and Meso-dermal Defects. (1) Gargoylism (Hurler's disease) has been confused with the generalized type of Morquio Brailsford disease. In addition to the cartilage irregularities there are hepatosplenomegaly, mental changes, corneal opacities, and profuse purulent rhinorrhoea.

(2) Chondro-ectodermal dysplasia was described by Ellis and van Creveld (1940) in three infants with bone changes resembling achondroplasia but without involvement of the base of the skull. In addition there were polydactyly, defects of the hair and nails, and congenital morbus cordis.

(3) In Maffucci's syndrome the dyschondroplasia is associated with multiple angiomata.
Many other syndromes may occur in which combinations of the various chondral growth disturbances are associated with ecto- and mesodermal abnormalities. We recently saw a young Indian girl who had bone changes resembling achondroplasia in one half of the skeleton and changes of osteochondrodystrophia deformans in the remainder of the skeleton.

\section{Summary}

Four cases of osteochondrodystrophia deformans (Morquio's disease) are described.

Two of the cases are of pure African native stock but the others are of mixed African and coloured stock. These appear to be the first reported cases occurring in persons not of pure European racial origin.

Consanguinity of the parents is present in three cases.

The blood chemistry investigations show no significant departure from normal.

A close relationship exists between the many different varieties of dyschondroplasia.

The patients were admitted to the paediatric unit of the Coronation Hospital under Dr. S. Selby. We wish to thank him for permission to publish the case reports and for his interest and encouragement.

We are indebted to Dr. M. Findlay for helpful advice on the radiological aspects, and to Dr. E. Samuel for advice and assistance in the preparation of this paper.

\section{REFERENCES}

Brailsford, J. F. (1944). 'The Radiology of Bones and Joints,' 3rd ed. London. (1931). Brit. J. Radiol., 4, 83.

Ellis, R. W. B. (1940). Archives of Disease in Childhood, $15,215$.

, and Creveld, S. van (1940). Ibid., 15, 65.

Henderson, J. L. (1940). Ibid., 15, 201.

Jacobsen, A. W. (1939). J. Amer. med. Ass., 113, 121.

Meyer, L., and Brennemann, J. (1932). Amer. J. Dis. Child., 43, 123.

Morquio, L. (1929). Arch. Méd. Enf., 32, 129. Quoted by Meyer, H. F., and Brennemann, J.

Ruggles, H. E. (1931). Amer. J. Roentgenol., $25,91$.

Shelling, D. H. (1947). In Brennemann's 'Practice of Pediatrics,' vol. 4, ch. 29. Hagerstown, Maryland. 